\title{
Overview and Insight from the China Research Report on the Global Youth Survey of Social and Emotional Skills by the Organization for Economic Cooperation and Development
}

\author{
Fengping Zhao ${ }^{1}$, Weijie Meng ${ }^{2}$, Fangmei $\mathrm{Li}^{3}$, Longjun Zhou ${ }^{4}$ \\ 1. Shandong Changle No.2 Middle School, Changle 262400, China \\ 2. Nanjing Yutong Experimental School, Nanjing 211100, China \\ 3. Nanjing Dianji Institute of Psychological Education, Nanjing 210000, China \\ 4. Jiangsu Second Normal University, Nanjing 211200, China
}

\begin{abstract}
Social and emotional skills are important for students in 21st century study, life, and future work. In 2018, the Organization for Economic Cooperation and Development (OECD) officially launched the first round of social and emotional skills tests for 10-year-old and 15year-old students worldwide. After 3 years of research, the first round of global data collection ended and at the end of 2019 the OECD published the Social and Emotional Ability Assessment International Report. As one of the participating cities, Suzhou, China, successfully completed the first round of testing and released a series of reports. This article summarizes the research work of the OECD and China on social and emotional capabilities of students and discusses a few insights from the data.
\end{abstract}

Best Evidence in Chinese Education 2021; 9(1):1169-1195.

Doi: 10.15354/bece.21.re055.

How to Cite: Zhao, F., Meng, W., Li, F., \& Zhou, L. (2021). Overview and insight from the China research report on the global youth survey of social and emotional skills by the Organization for Economic Cooperation and Development. Best Evidence in Chinese Education, 9(1):1169-1195.

Keywords: Student Social and Emotional Abilities, Educational Evaluation, OECD, China, Education 
Zhao et al. China Report on the Global Youth Survey of Social and Emotional Skills by the OECD.

About the Author: Fengping Zhao, Shandong Changle No.2 Middle School, Changle 262400, China. E-mail: zhaofengping5138@163.com

Weijie Meng, Principal of Nanjing Yutong Experimental School, 22 Jiangjun Avenue, Jiangning District, Nanjing 211100, Jiangsu, China. E-mail:13608955415@126.com

Fangmei Li, Nanjing Dianji Institute of Psychological Education, Nanjing210000, Jiangsu, China. E-mail: 1037576462@qq.com

Correspondence to: Longjun Zhou, Jiangsu Second Normal University, Nanjing 211200, Jiangsu, China. E-mail: 294437034@q9.com

Conflict of Interests: None.

(C) 2021 Insights Publisher. All rights reserved.

cC) (i) (3) Creative Commons Non Commercial CC BY-NC: This article is distributed under the terms of the Creative Commons Attribution-NonCommercial 4.0 License (http://www.creativecommons.org/licenses/by$\mathrm{nc} / 4.0 /$ ) which permits non-commercial use, reproduction and distribution of the work without further permission provided the original work is attributed by the Insights Publisher. 
OCIAL and emotional abilities are widely regarded by researchers as core elements of human growth and development. The United Nations Educational, Scientific and Cultural Organization (UNESCO) proposed that education in the 21st century must break the constraints of a singular emphasis on academic, scientific and technological ability. Rapid world changes and increasing maturity of the application of automation technology, make the development of social emotional abilities crucial (UNESCO, 2019). The Organization for Economic Cooperation and Development (OECD) also emphasizes that, in modern life, children's success is inseparable from a complete set of cognitive, social and emotional skills, such as achieving goals and interacting with others. The ability to cooperate effectively and manage emotions is essential to meet the challenges of the 21 st century (OECD, 2015). Therefore, it has become the consensus of educators worldwide to regard social and emotional abilities as an important component of student training.

OECD started the Survey of Social and Emotional Skills (SSES) research in 2013, with the aim to promote the balanced development of cognitive ability and social emotional ability. Compared to earlier started projects that focused on cognitive ability (e.g., PISA, IELS, PIAAC and others), the SSES project fills a gap in the OECD ability assessment project and guides the future development of global education and the shift in the focus of talent training. The SSES project is not a simple international competition. Rather, it aims to discover the effectiveness and blind spots of various countries' education policies through evaluation and research. The objective is to analyze problems existing in the development of education in various countries and show their respective achievements and advantages, to provide countries around the world with experiences from other countries.

In 2018, the Social and Emotional Skills Assessment was officially launched. At the end of 2019, the first round of the official assessment was completed in 10 cities from nine countries around the world. On 7 September 2021, the OECD released a global assessment report (OECD, 2021) at its headquarters in Paris based on this survey. The report provides an overview of the social and emotional abilities of young people in the ten participating cities, and reports on the factors that affect social and emotional abilities. From an international perspective, it provides information for the improvement of social and emotional abilities, educational decision-making and educational practice in various countries.

\section{Definition and Value of Social and Emotional Capa- bilities}

\section{Definition of Social and Emotional Competence}

The proposed assessment of social emotional ability is based on research of social and emotional ability. Social skills are considered a cognitive skill that allows effective performance in a group. Social skills encompass skills found in the three dimensions of communication, cooperation and identification. These skills ultimately enable individu- 
als to show appropriate behaviors during group activities (Gold, 2009), including communication skills and the ability to cooperate with others. Emotional ability refers to a person's ability to master their own emotions, to bear external pressure, and to use emotions to facilitate interpersonal relationships, including empathy, emotion recognition, emotion regulation, understanding of experiences, and recognition of one's own desires (Huy, 1999). Emotional competence develops through interpersonal communication, social structure and culture (Turner \& Stets, 2005). Thus, some scholars combine these abilities under the term social emotional competence.

Elias et al. (1997) defined social and emotional competence as the ability to understand, manage and express the social and emotional aspects of life. This ability can help individuals successfully manage their life affairs, such as learning, establishing interpersonal relationships, solving daily problems, and adapting to complex needs in growth and development. Osher et al. (2016) suggested that social emotional competence is a series of core competencies related to self-adjustment and social development that children master and apply, including recognizing and managing emotions, setting and achieving positive goals, appreciating others, establishing and maintaining good relationships, and making responsible decisions.

At the national level, the British Ministry of Education defines socialemotional competence as including the five aspects of "self-awareness, managing feelings, motivation, empathy, and social skills" (Lendrum \& Humphrey, 2010). Singapore's Ministry of Education suggests social-emotional competence is at the core of 21 st century skills and goals, describing social emotional competence as "skills for recognizing and managing emotions, developing care for others, making responsible decisions, building positive relationships, and effectively handling challenging situations" (Tan et al., 2017). Australia also pays attention to the development of students' social and emotional well-being; its definition includes seven dimensions: overall social and emotional health, psychological flexibility, positive social orientation, positive work orientation, positive school indicators, positive family indicators, and positive community indicators (Frydenberg et al., 2017). China's "Social Emotional Learning and School Management Improvement Project" team proposed that social emotional competence is the ability to acquire knowledge, skills, and attitudes to enable the emotional experience of understanding and managing relationships with themselves, with others, and with the collective; it includes self-awareness and self-management, cognition and management of others, collective cognition and collective management (Mao et al., 2018).

Related organizations have also expounded on the definition of social emotional competence. For example, the American non-profit organization, Collaborative for Academic, Social, and Emotional Learning (CASEL), works from a perspective of joint development of human cognition, sociality, and emotion, suggesting that social emotional capabilities specifically include self-awareness, self-management, social awareness, relationship skills, and responsible decision making. The World Economic Forum (2016) summarized ten social and emotional skills, including four competencies (problem solving/critical thinking, creativity, communication, and collaboration) and six 
character qualities (curiosity, initiative persistence/grit, adaptability, leadership, social and cultural awareness). The Organization for Economic Co-operation and Development (OECD) defines social and emotional skills as an individual ability consisting of a characteristic quality of individuals facing different situations. The OECD (2015) divides this quality into three categories: 1) the ability to achieve goals, including persistence/perseverance, self-control, and the passion to achieve goals; 2) the ability to collaborate with others, including social interaction, respect, and care; and 3) emotional management capabilities, including self-esteem, optimism, and self-confidence.

Thus, while the definition of social emotional abilities differs among theoretical foundations and research perspectives, scholars, organizations, countries, and researchers, all definitions emphasize the involvement of an individual's abilities to manage internal and interpersonal domains.

\section{The Value of Social and Emotional Capabilities}

Social and emotional abilities are of great significance to individual development and $\mathrm{i}$ affect students' academic and life success. Numerous domestic and foreign scholars have conducted research on the value of social and emotional abilities from different perspectives. Such research has helped individuals achieve professional success and happiness in life and has promoted the overall ability of individuals to meet the requirements of future social contexts. Several studies focus on the impact of social and emotional skills on student academic achievement.

\section{Social and Emotional Abilities Affect Academic Perfor- mance}

Nearly all empirical studies on social emotional ability have confirmed that social emotional ability has a positive impact on students' academic performance. Durlak et al. (2011) conducted a meta-analysis of the results of the Social and Emotional Learning (SEL) program covering 213 schools and 270,034 students from kindergarten to high school. Using meta-analysis of the results of the program revealed that compared to control students, students who received the intervention of the SEL project had an $11 \%$ higher performance (Alzahrani et al., 2019). The authors also note that social and emotional abilities have an impact on children's learning outcomes and their ability to engage in good behavior.

Elias (2008) studied third grade students from urban ethnic minorities in the United States and showed that the social emotional ability of these minority students had significant predictive ability on their academic performance, with a regression coefficient of 0.619. Zhou (2010) and Liu (2017) found that, in Chinese students, a complex interaction exists between children's personality, academic performance, and social adjustment. They also found that social and emotional abilities of students, as assessed by parents, can significantly predict student academic performance (regression coefficient $=0.37$ ). Liu $(2017)$ found that self-esteem, self-motivation, and emotional percep- 
tion components of the trait emotional intelligence can significantly predict mathematical ability in primary school students.

\section{Social and Emotional Abilities Affect Personal Income}

Many empirical studies have shown that cognitive ability has a positive effect on wages and economic growth (Hanushek, 2013). The potential explanatory effect of noncognitive abilities on income, independent of cognitive abilities, has also received attention (Huang \& Xie, 2017). Heckman (2006) found that non-cognitive abilities not only affect educational decision-making, but also affect an individual's social performance and professional income in a study of participants in the General Educational Development (GED) program in the United States. Some scholars suggest that non-cognitive skills, like obedience, loyalty and persistence, are more important than cognitive skills, especially in the low-skilled labor markets (Bowles \& Gintis, 2002), such as the service industry (Mýtna Kureková et al., 2016). Other studies have supported this conclusion. Adhitya et al. (2019) analyzed data from the Fifth Indonesia Family Life Survey (IFLS), and found that personality characteristics affect job prospects in the labor market. For example, conscientiousness and extroversion had a significant positive effect on job success. Responsible people tend to work hard, be productive, punctual, and organized. Extroverted individuals were more willing to take on social activities and leadership roles, and this had a positive impact on their careers.

Succi \& Canovi (2020) used a questionnaire to compare views of students and employers on the importance of soft skills in different European countries and found that $86 \%$ of respondents indicated that they have paid increasing attention to soft skills in the past 5-10 years, and that companies believe soft skills are more important than academic performance of students/graduates.

\section{Social Emotional Ability Contributes to Personal Happiness}

Harvard University began a comprehensive longitudinal study in 1938 that has lasted nearly a century. The longitudinal study involves three classes of people, including 268 Harvard graduates, 456 urban blue-collar males, and 90 high-IQ middle-class women. Researchers tracked participants from birth to old age to explore correlates of happiness and longevity. In 2012, the project leader released an adult development prospective report that, combined with the analysis of tracking data in these 814 people for nearly a century, found that happiness is closely related to good interpersonal relationships and an optimistic attitude (Vaillant, 2012).

Other research results also show that personal happiness is closely related to social emotional ability. On the one hand, good social and emotional abilities can continuously and cumulatively affect other areas of an individual's life, help students better adapt to school life, achieve better academic performance, obtain a higher professional status, and effectively enhance life satisfaction (Heckman \& Kautz, 2012). On the other hand, the level of students' social and emotional ability is directly related to their future marital status, health status, and moral level. For example, social and emotional abilities 
play an important role in improving health-related outcomes (e.g., obesity, cardiovascular and cerebrovascular diseases), which is beneficial to their health and longevity (OECD, 2015; Atkins et al., 2020). Perseverance, emotional stability and social skills enable people to better transform ideas into actions, establish positive relationships with family, friends and communities, avoid unhealthy lifestyles and dangerous behaviors, reduce anti-social behaviors, and protects individuals from infringements of aggressive behavior, leading to a greater positive life experience (Liu \& Liang, 2021).

OECD research also indicates social and emotional skills have a positive impact on personal well-being and social progress; such skills act by promoting a healthy weight, alleviating depression, reducing problem behaviors, increasing subjective wellbeing, improving life satisfaction, and increasing helpful life behaviors. Increased higher education, enhances the ability of individuals to translate intentions into actions, and improves the life prospects of disadvantaged children. At present, most OECD countries and partner economies recognize the need to strengthen the development of students' social and emotional capabilities. Both national and local policy documents of these countries emphasize the importance of enhancing a student's autonomy, sense of responsibility, and ability to cooperate with others.

\section{OECD's Research and Promotion of Social and Emo- tional Capabilities}

Although scholars have reached a basic consensus on the definition and value of social and emotional competence, there seems to be little on how to best measure these skills. Based on the CASEL competency framework, nine social and emotional assessment tools have been identified that can be used for the reference and selection of school districts and schools (Wiglesworth, Humphrey, Kalambouka \& Lendrum, 2010). A Social Emotional Competence Questionnaire (SECQ) based on the CASEL theoretical model has been developed that aims to assess children and adolescents (grades 3-12) based on self-reports about themselves and others, and how they respond in home, school and community environments (Haggerty et al., 2011; Zhou, Ee, 2012).

The OECD has been measuring the abilities of students since the 1990s using large-scale international education evaluation projects to allow participating countries to examine their own education quality and fairness and to develop efficiency from the perspective of international comparison. This allows countries to stabilize and improve education by monitoring the indicator system and to promote education reform and development. Since the beginning of the 21st century, the OECD has included measures of students' non-cognitive abilities, with the goal of quantifying other aspects of personal development through assessment of students' social, emotional and other noncognitive abilities.

From March 23 to 24, 2014, policy makers, including 11 education ministers and deputy ministers, took part in an OECD informal ministerial meeting on skills for social progress in Sao Paulo, Brazil. They agreed it was necessary to promote development of a "complete child" with a balanced set of cognitive, social and emotional skills 
so that they can better face the challenges of the 21st century (OECD, 2015). On March 10, 2015, the OECD released "Skills for Social Progress: The Power of Social and Emotional Skills," a report that presents the OECD's comprehensive analysis of the role of emotional skills, and a strategy to improve these skills. The report includes an analysis of the impact of social and emotional skills on individual happiness and social progress (covering all aspects of life, including education, labor market output, health, family life, citizen participation, and life satisfaction). The report draws four important conclusions: 1) sense of responsibility, social skills, and emotional stability are the most important dimensions of social and emotional skills affecting children's future prospects; 2) early intervention in social and emotional skills can effectively improve skills and reduce education, labor market, and social inequality; 3) within a cultural and linguistic background, social and emotional skills can be reliably assessed; and 4) providing relevant information and formulating guidelines will help educate stakeholders to promote children's social and emotional development (OECD, 2015). On this basis, the OECD organized and established a social and emotional skills research project team in 2016 to carry out the evaluation of social and emotional skills and to set up a steering committee composed of internationally renowned experts that could provide guidance and attract participating countries and regional representatives.

In December 2017, the OECD released the report, "Personality matters: Relevance and assessment of personality characteristics," that evaluated the socio-emotional skills of students aged 10-15 years-old in some cities and countries around the world over three years (OECD, 2017). The outcome was an approved monitoring tool of the development of students' social and emotional skills to explore the impact of personal, family and school characteristics on the development of students' social and emotional skills. Further, the monitoring tool can be used to assess which emotional and social skills best predict students' later achievements. Decision makers and practitioners can then be provided with reliable, effective and internationally comparable information on the development of students' social and emotional skills. In addition, policies and measures that can be implemented for improvement can be made available.

\section{Research Subjects}

SSES is aimed at students aged 10 years and 15 years. The project team believes that the 10-year-old student group (between 10 years and 3 months to 11 years and 2 months) is able to express personal feelings relatively stable. This earliest age group is in the middle stage of elementary school. The 15-year-old student group (15 years and 3 months to 16 years and 2 months) is in formal education, has not yet undergone vocational education triage, and is done in cooperation with the International Student Assessment Project (PISA) The student groups in middle school are consistent, which is convenient for data comparison.

\section{Research Model}


Since Goldberg first proposed the "Big Five" personality factors (openness, conscientiousness, extroversion, affinity, and neuroticism) in 1971, these personality factors have been used in large sample research. Repeated discovery until it becomes a factor of a personality trait model recognized by the western psychology circle (Mueller \& Plug 2006). The social and emotional competence assessment framework constructed by the OECD is based on the Big Five personality traits model, and considers five dimensions: 1) task performance (conscientiousness); 2) emotional control (emotional stability); 3) collaboration (affinity); 4) openness; 5) interactions with others (extroversion) (Kankaraš, 2017).

Task performance includes achievement motivation, i.e., setting high standards for oneself and working hard to achieve these standards; self-discipline, i.e., controlling impulse, delaying gratification and maintaining focus; conscientiousness, i.e., fulfilling promises; and perseverance, i.e., persistence and commitment to goals. Emotional control includes stress-reduction (effectively adjusting anxiety and coping with pressure); restraint (controlling temper and emotions); optimism (a positive attitude toward individuals and life). Interactions with people others includes vitality (staying active throughout the day); decisiveness (controlling behavior); and being kind (willingness to interact with others). Collaboration includes empathy (looking at problems from the perspective of others); cooperation (getting along with others); and trust (believing that most people have good intentions). Openness includes curiosity (a willingness to learn and explore new things); creativity (generating new ideas or products); and inclusiveness (being open to diverse views). Complex skills include self-efficacy (belief in one's ability to complete tasks and achieve goals); critical thinking (being able to reflect on oneself and base ideas on independent thinking and critical analysis); and metacognition (recognizing and adjusting the thinking process and subjective experience).

Using the Big Five Personality traits, the OECD selected three to four social and emotional abilities under each dimension, for a total of 19 skills. Each skill is described by approximately 10 items, and a Likert five-point scale used by survey respondents for each question. After the second round of on-site testing in 2018, the four skills of perseverance, courage, metacognition and critical thinking, which had low reliability and efficiency, were deleted, leaving a final version with 15 skills (Figure 1). Through surveys of students, parents and teachers, mutual confirmation is used to measure the development level of students' social and emotional abilities and to relate other variables to the development of social and emotional abilities (Chernyshenko et al., 2018).

\section{Research Methods}

The SSES project uses a random stratified sampling method, requiring each participating country or region to randomly select schools first, and then randomly select students who meet the age requirements from within these schools. The SSES project requires that each participating country or region select 3,000 10-year-old and 15-year-old students. In addition to the information from these 6000 students, information about their parents, teachers, and schools are also needed because the information collected by the 


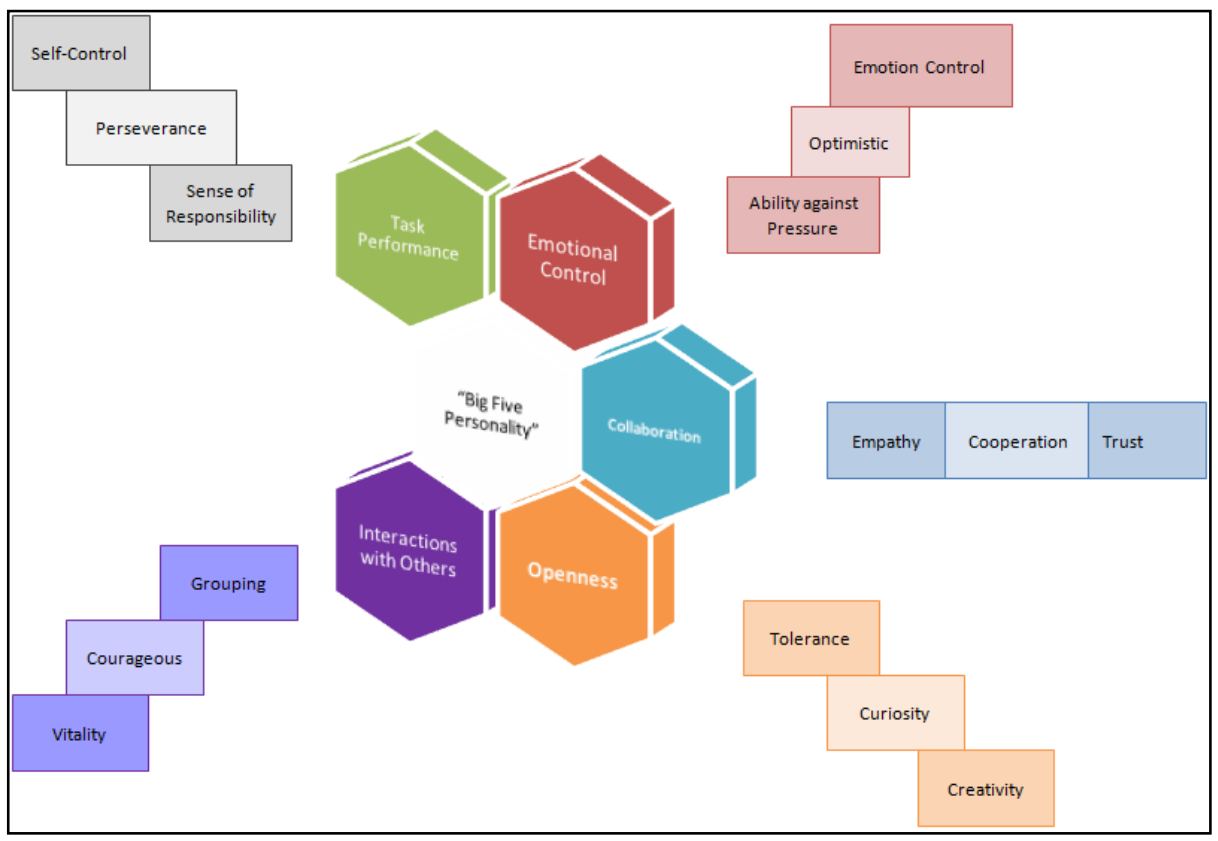

Figure 1. The Five Dimensions and 15 Sub-Competencies in the Assessment.

SSES project includes not only information about students' social and emotional skills, but also information about their long-term home and school environment. The project team developed four types of questionnaires; one for students and one for each of parents, teachers, and principals closely related to the growth of the students. At the same time, schools provided data on each student's academic performance and school behavior. Triangulation of measures was used to improve objectivity and accuracy in measures of students' social and emotional abilities (Kankaraš et al., 2019).

Student questionnaires included personal background information, such as student's learning expectations, ideal jobs, interactions with parents and friends, school life, etc., as well as self-evaluation information on social and emotional skills and behavior. Each selected student had a parent or guardian fill out a parent questionnaire, which includes family background information, such as family economic and social status, parent-child interaction information, child-child interaction information, parent's understanding and practice of social and emotional skills. In addition, parents were asked to evaluate their child's social and emotional skills. Each selected student also had a teacher familiar with him or her fill out the teacher questionnaire. The teacher questionnaire includes background information on the teacher, such as teaching practice, professional development, and the teacher's understanding and practice of social and emotional skills. The teacher also provided an evaluation of the student's social and emotional skills. Finally, the principal of each selected middle school filled out a principal questionnaire. The principal questionnaire includes information on the community where the school is located, the overall situation of teachers and students, the school's 
teaching and evaluation policies regarding social and emotional skills, and the organization and management of the school (Fang, 2020).

After the selection of survey items in 2017, followed by the field test in 2018 and official test results in 2019, the OECD's formal assessment of social and emotional abilities finally settled on a student questionnaire containing 65 questions (the 15 -yearold group has 68 questions). The parent questionnaire contains 53 questions, the teacher questionnaire contains 34 questions and the principal questionnaire contains 32 questions. It is worth noting that after the OECD integrated the data analysis of all participating countries, some items that did not meet measurement standards were deleted for the final form of the test questionnaire (OECD, 2021). After two years of work, on September 7, 2021, the OECD presented the first round of evaluation results of the Global Social and Emotional Ability Research Project.

\section{A Survey of the Social and Emotional Abilities of Chinese Adolescents}

In the international comparative study of social and emotional skills organized by the OECD, 10 cities in 9 countries, including the United States, Russia, Finland, South Korea, Canada, Italy, Portugal, and Turkey, participated in the project. China was also a participating country with151 primary and secondary schools in six districts and four county-level cities under the jurisdiction of Suzhou City participating in the assessment project, including 3,647 10-year-old students and 3,621 15-year-old students. After comparative analysis of the data, the project team positioned the development level of Chinese students' social and emotional ability development in different age stages in the world, further explored factors affecting the development of Chinese students' social and emotional abilities, and proposed intervention measures.

\section{Overview of the SSES Project in China}

Advancement of the SSES project is divided into three phases: 2017 is the tool development phase (item trial); 2018 is the field test phase (field test); and 2019 is the official evaluation phase (main study). In April 2018, China formally joined the project, and subsequently carried out translation of various instruction manuals, localization of assessment tools, training of assessors, and training of school coordinators, school sampling, and on-site testing. In November 2018, the China Social and Emotional Ability Project Team cooperated with the Suzhou Bureau of Education to conduct on-site tests with 1,500 students from 30 primary and secondary schools in 10 districts and counties of Suzhou. At the same time, 1,500 students' parents, 858 teachers and 30 principals filled out a questionnaire survey. From the end of 2018 to the first half of 2019, the project team conducted follow-up surveys, data sorting and classification, and wrote field test survey reports to prepare for the official evaluation in the second half of 2019.

\section{Sample Selection}


In the next formal testing phase, all schools in the ten districts and counties of Suzhou participated in sampling, and random sampling was conducted at the levels of schools and students. For school sampling, 76 schools were sampled from 387 primary schools (10-year-old students), and 75 schools were sampled from 88 high schools and vocational schools (15-year-old students). For student sampling, based on the teacherstudent association table provided by the sampled school, 50 students were randomly selected among students enrolled at the school. After these two steps, a total of 7,550 primary and secondary school students from 151 primary and secondary schools had been selected. In the formal testing phase, the overall participation rate of the sampled students was as high as $96.26 \%$, and a total of 7,268 students completed all tests, representing 150,964 elementary and middle school students in Suzhou. Among the 7,268 students in the final sample, 3,647 (50.2\%) were in the 10-year-old group, 3,621 (49.8\%) were in the 15-year-old group; 3,838 (52.8\%) were boys, 3,417 (47\%) were girls, and $13(0.2 \%)$ had unknown gender); 3,447 students (47.4\%) were studying in schools in the downtown area, and 2,459 students $(33.8 \%)$ were studying in schools in counties and towns. There are 1,362 students in rural schools (18.7\%). Among the 15-year-old students, $2,811(77.6 \%)$ and $810(22.4 \%)$ were enrolled in regular high schools and vocational high schools, respectively. While carrying out the student survey, another 7,136 parents, 3,732 teachers and 151 principals participated in filling out the parent questionnaire, teacher questionnaire and principal questionnaire respectively (Zhang et al., 2021).

\section{Evaluation Tools}

The social and emotional ability evaluation items included four types of evaluation questionnaires: student, parent, teacher and principal questionnaires. Among them, the student questionnaire mostly concerns students' self-assessment of their social and emotional abilities, but also includes items related to the student's school and family environment. The parent questionnaire includes information about the child's social and emotional abilities, the child's growth history, the family environment, and the parents' social and emotional abilities. The teacher questionnaire collects the teacher's assessment of the student's social and emotional abilities and the teacher's report on the school's learning environment. The principal's questionnaire covers the broader social background of the school and its students, and the existing resources and programs at the school aimed at improving the learning environment.

The 2019 OECD Official Assessment of Social and Emotional Ability provided seven online assessment questionnaires at the Suzhou assessment site. There were two student questionnaires, one for the 10-year-old group and one for the 15-year-old group. The parent questionnaire for these two age groups is the same. The teacher questionnaire consists of two parts. The first part, completed by teachers of both age groups, includes the teacher questionnaire survey and auxiliary test anchor questions. Every participating teacher completed this part. The second part had two versions, one for the 10-year-old group and the other for the 15-year-old group. The teacher was asked to 
complete this part for each student who "he/she knows best." The main questionnaires for the two age groups are the same (Zhang et al., 2021).

\section{Variable Table of Influencing Factors}

Data analysis also examines factors that affect students' social and emotional abilities. Factors come from the five main categories of background variables, student variables, teacher variables, school variables, and family variables. The relationship between social, family and student variables is also examined, for a total of 30 basic measures, as shown in Table 1.

\section{China SSES Test Results}

Data analysis results are presented in three parts. The first part uses descriptive statistics to show the overall scores of social and emotional abilities, as well as the Big Five personality traits and its 12 sub-categories in terms of age, gender, urban and rural areas, and school categories. The second part uses multiple regression analysis to explore the effect of social and emotional abilities of 10-year-old and 15-year-old students on outcome variables, such as personal life and behavior. The third part uses multiple regression analysis to examine the influencing factors of social and emotional abilities, including the effects of background variables, student variables, teacher variables, school variables, and family variables.

\section{The Development Level of Chinese Students' Social and Emotional Abilities}

\section{- Task Abilities}

Students in the 10-year-old group have higher task ability than those in the 15-year-old group, and the monthly age within the 10-year-old and 15-year-old groups is positively correlated with task ability. Within age groups, 10-year-old girls have higher task ability than boys, while the task ability of 15-year-old boys is higher than that of girls. Urban students have higher task abilities than rural students (Gao et al., 2021).

\section{- Emotional Abilities}

Students in the 10-year-old group generally have higher scores in the emotional regulation dimension than those in the 15-year-old group. Students in the 10-year-old group generally believed that they were very optimistic and did a good job of emotional control, but the parents of the 10-year-old group did not agree. Contrarily, the 15-year-old students' self-evaluation scores were lower than the scores from their parents. Students in both age groups were below the international average for stress resistance, which also has the lowest score among the 15 abilities. Boys perform better than girls overall when it comes to emotional regulation, especially in terms of stress resistance. The performance of students in urban areas is better overall than that of students in rural areas (Liu et al., 2021).

\section{- Collaboration}




\section{Table 1. Table of Variables Affecting Social and Emotional Abilities.}

\begin{tabular}{ll}
\hline Main Variable & Basic Variable \\
\hline Background & $\begin{array}{l}\text { Gender; age; socio-economic status (parents' highest education, family possessions, } \\
\text { family equipment, family book collection) }\end{array}$ \\
\hline Student & $\begin{array}{l}\text { Sense of security; friendships; good habits of friends; high expectations of friends; } \\
\text { extensive social relationships; indoor activity time; online time; outdoor activity time; } \\
\text { growth mindset }\end{array}$ \\
\hline Teacher & $\begin{array}{l}\text { Teaching age; educational background; opportunities to participate in social- } \\
\text { emotional ability-related training (referred to as "training opportunities"); frequency of } \\
\text { participation in social-emotional ability-related training (referred to as "training fre- } \\
\text { quency"); teacher-student relationship; high teacher expectations, etc. }\end{array}$ \\
\hline School & $\begin{array}{l}\text { School belonging; school cooperation atmosphere; school competition atmosphere; } \\
\text { campus bullying; extracurricular activities, etc. }\end{array}$ \\
\hline Family & $\begin{array}{l}\text { Parenting style (understanding father/understanding mother, punitive father/punitive } \\
\text { mother); parent-child issues; high expectations of parents }\end{array}$ \\
\hline
\end{tabular}

The students in Suzhou, China self-report collaboration as quite high, especially empathy, trust, and cooperation abilities, which are higher than the international average. The self-evaluation score of the 10-year-old group is significantly higher than that of the 15year-old group, while the evaluation scores of parents and teachers of the two age groups are relatively close. The collaboration ability of female students in the 10-yearold group is higher than that of boys, while in the 15-year-old group, boy collaboration scores are higher than that of girls. In addition, students in central urban areas are generally better than rural students in collaboration ability (Tang et al., 2021).

\section{- Openness}

For the average of the three sub-categories of openness (tolerance, curiosity, and creativity), the self-evaluation of Suzhou students is higher than the international average. In contrast, the 15-year-old group's self-evaluation is lower than that of the 10-year-old group, and boys' self-evaluation is higher than that of girls, especially in terms of creativity. This gap in creativity scores between boys and girls is even larger in the 15-yearold group. The openness of students in central urban schools is significantly higher than that of rural students, but the effect size is not large (Shao et al., 2021).

\section{- Communication Ability}

The overall score of Suzhou students in communication ability is higher than the world average, indicating that the confidence of Suzhou students in themselves is higher than the international average. The difference in self-evaluation of communication ability between students in the 10-year-old group and the 15-year-old group is relatively large, while the gap in parental evaluation for the two age groups is relatively small. There are also significant differences in the communication abilities of students of different gender groups. Girls in the 10-year-old group show significantly higher level of sociability and courageousness than the boys. The vitality of boys in the 10-year-old group and 15year-old group are significantly higher than that of girls. Student communicative ability 
in central urban schools is higher than that in county and rural areas. There is no significant difference in the communication ability between ordinary high school and vocational high school students (Huang et al., 2021).

The scores of students in all 15 social and emotional abilities are slightly higher in the 10-year-old group than in the 15-year-old group (the standard deviation of the 10year-old group is 83.68-124.40, and the standard deviation of the 15-year-old group is 73.00-91.94). Within the two age groups, no significant gender differences are present in most social and emotional abilities. However, among the 10-year-old students, girls scored higher in most social and emotional abilities, especially in empathy, cooperation, rapport, perseverance and tolerance, whereas among the 15-year-old students. With the exception of tolerance, boys scored higher than girls in most social and emotional abilities. The social and emotional abilities of most students are not significantly affected by the school's socioeconomic level for either age group. However, a general trend exists for the scores of social and emotional abilities of students from schools with high socioeconomic levels to be slightly higher than those of students from schools with low and medium socioeconomic areas. Students in ordinary high schools and vocational high schools have no significant differences in social and emotional abilities, but students in ordinary high schools generally score slightly higher in tolerance, curiosity, and creativity.

\section{Factors Affecting the Development of Chinese Students' So- cial and Emotional Abilities}

Elucidating the factors that affect the development of Chinese students' social and emotional abilities is an important goal of the evaluation project. In this regard, China's assessment project starts with the analysis of social background, summarizes the relationship between social and emotional abilities and various influencing factors from background variables, individual student factors, family factors and school factors, and collects students' non-intellectual data through field investigations. The data on development level are then placed in the international environment for horizontal comparison, and finally specific educational intervention measures are proposed.

In the evaluation report of task ability, family education and school education have a great influence on students' task ability. Among them, in family education, different types of parents have different effects on students' task ability. Understanding mothers have a stable and positive influence on the task ability of students in both age groups, while the influence of punitive parents is more complicated. Punitive mothers in the 10-year-old group have a positive effect on students' task ability, but punitive fathers have a negative effect on perseverance. In the 15-year-old group, punitive fathers have a positive influence on students' task ability and punitive mothers have a negative effect on students' self-control and responsibility. In school education, teacher-student relationship, school belonging, and school cooperation atmosphere have the greatest impact on students' task abilities, reflecting the key role of school environment in the formation of students' responsibility levels (Gao et al., 2021). 
Of the many factors that affect emotional ability, more than 30 variables in the five categories of background, student, teacher, school, and family all have consistent and significant effects on students' emotional regulation abilities, and most of these are positive effects. In background variables, the higher the parents' educational background and the greater the number of family possessions and book collections, the better the students' emotional regulation ability. In student variables, security, friend relationships, outdoor activity time and growth-oriented thinking have a significant positive impact on emotional regulation, while online time has a significant negative impact on emotional regulation. In teacher variables, the quality of the teacher-student relationship is positively correlated with a student's emotional regulation, and teachers' participation in social and emotional ability cultivation training helps the students' ability development. In school variables, the three variables of school atmosphere of cooperation, extra-school activities and especially, the sense of belonging to school significantly increase development of students' abilities. In family variables, understanding parents, especially understanding fathers, have a positive effect on the development of children's emotional regulation ability, while parent-child problems have a negative effect on ability development (Liu et al., 2021).

In the analysis of factors affecting collaboration ability, the 30 scales can be divided into positive and negative. Most are positive factors, including family possessions, family collection of books, sense of security, friendship, good friends, indoor activity time, outdoor activity time, understanding mothers, understanding fathers, high expectations of parents, teacher-student relationship, school belonging, school atmosphere of cooperation, and off-campus activities. Negative factors for collaboration include online time, parent-child problems (Tang et al., 2021).

The openness of students is also affected by student, teacher, school and family factors. For background variables, parents' highest education level, family possessions, and family's collection of books have a significant positive impact on the openness of both 10-year-old and 15-year-old groups. Among student variables, security, friendship, good habits, outdoor activities, time- and growth-oriented thinking have a significant positive impact on the openness of students. One age group difference is that "widespread social friendship" has a negative impact on creativity in 10-year-old students, while it has a positive impact on creativity in 15-year-old students. Teacher education and teacher-student relationship have a significant positive impact on openness for both groups of students. Among school variables, the sense of belonging to school, school atmosphere of cooperation, school atmosphere of competition, and off-campus activities all have significant positive effects on openness. Among family variables, parenting style and parental expectations have a significant impact on students' openness. Students in both age groups with understanding parents have a greater openness. In the 10year-old group, punitive mothers also have a positive impact on students' openness. Parent-child difficulties have a significant negative impact on openness (Shao et al., 2021).

Students' communicative ability is also affected by numerous variables. In student variables, sense of security, friendships, friends with good habits and personal out- 
door activity time significantly increase communication abilities of 10-year-old and 15year-old students, while time spent online has a significant negative effect on the communication ability of students. The teacher-student relationship has a significant positive effect on the communication ability of both 10 and 15-year-old students. The sense of belonging to school and extracurricular activities significantly affect students' communicative ability in a positive way. Parental rearing styles have a significant positive impact, while parent-child problems have a significant negative impact, on students' communication skills (Huang et al., 2021).

From the general analysis results, the sense of belonging to school, cooperative learning atmosphere, friendships, and sense of security are positively correlated with the social and emotional abilities of most students. High scores in school belonging are closely related to social and emotional abilities. Parent-child issues and greater participation in daily online activities are negatively correlated with all social and emotional abilities.

\section{The Relationship between Students' Social and Emotional Abilities and Personal Life and Behavior}

In addition to the basic level assessment, the Chinese assessment project team analyzed the correlation between 15 social and emotional abilities and the personal life characteristics and behavioral performance of students in the 10-year-old and 15-year-old groups. Characteristics included academic performance (language, mathematics and art), psychological well-being (current psychological well-being, life satisfaction and exam anxiety), and involved in classroom activities, smoking and 10 other behavioral indicators. Life satisfaction, current psychological well-being, and exam anxiety are similarly affected by a student's age and gender. Older students, especially older girls, showed lower life satisfaction and lower current psychological well-being, and higher test anxiety. In terms of related abilities, optimism is most closely related to life satisfaction and current psychological well-being, followed by vitality and trust. Exam anxiety is most influenced by anti-stress and optimism abilities of students (Yuan et al., 2021).

To measure behavior performance, the project team set up 10 and 14 behavior indicators in the questionnaire surveys of students, parents, and teachers for each age group, such as whether they are "honest" and "do housework," or "have difficulty concentrating." For the 15-year-old age group, additional behavior indicators were included, such as "handling the extra change", "playing truant", "and smoking" and "drinking." All 15 social and emotional abilities are negatively correlated with students' negative behaviors. For example, inattention and insomnia are negatively correlated with most social and emotional abilities. Especially in the 15-year-old group, all 15 social and emotional abilities are weakly correlated with bad behaviors such as absenteeism, smoking, and drinking, while positive behavior indicators, such as observing rules and participating in classroom activities, have moderate to strong correlations with most social and emotional abilities (Yuan et al., 2021). 


\section{Conclusions and Enlightenment}

China has begun to pay attention to improving students' non-cognitive abilities such as collaboration and emotional abilities. In June 2013, the Ministry of Education issued "Opinions of the Ministry of Education on Promoting the Reform of Comprehensive Evaluation of Education Quality in Primary and Secondary Schools," which noted that it is necessary to "effectively reverse the tendency of evaluating the quality of primary and secondary schools solely based on students' academic test scores and school enrollment rates, and promote the overall development of students." Healthy Growth, with key indicators such as personality quality, emotional behavior control, interpersonal communication and curiosity and thirst for knowledge, included in the annex "Comprehensive Evaluation Index Framework for Primary and Secondary Education Quality (Trial)" are all social and emotional skills. The main components of the survey have strong similarities with the corresponding indicators of the OECD's social and emotional skills (Ministry of Education of China, 2013).

In September 2016, the research report, "Core Competence of Chinese Student Development," was released. It clearly stated that students should have the necessary qualities and key abilities to adapt to lifelong learning and lifelong development. These key abilities are divided into three aspects: cultural foundation, independent development, and social participation. It is comprehensively expressed as the six qualities of humanistic background, scientific spirit, learning to learn, healthy living, responsibility, and practical innovation, which are further refined into 18 basic qualities such as humanistic feelings, aesthetic appeal, rational thinking, social responsibility, national identity, and labor awareness. In the document, non-cognitive ability is introduced into pedagogy research and education evaluation system, and development of non-cognitive abilities in young people is emphasized in basic education in China (Core Literacy Research Group, 2016).

However, according to the latest data from the International Student Assessment Project (PISA) released in December 2019, although Chinese teenagers ranked first in the world in the three cognitive abilities tests of reading, mathematics and science, they showed a low sense of belonging to the school, low levels of satisfaction with schools, lack of autonomy and self-consciousness for self-planning ( $\mathrm{Du}, 2019$ ), there is still much room for improvement in the non-cognitive abilities of Chinese students (Zhang, 2020).

The evaluation of social and emotional abilities carried out this time is a response to China's long-standing problems of emphasizing cognitive abilities and neglecting non-cognitive abilities: the cultivation of Chinese youth's social and emotional abilities is of great significance to the promotion of China's educational reform. This is not only the presentation of the SSES evaluation results, but also some enlightenment based on the analysis of the China Social and Emotional Ability Evaluation Report.

\section{Social and Emotional Abilities can be Improved with}

\section{Intervention}


The measurement results of social emotional skills only illustrate a state, and ultimately point to specific intervention methods. Social and emotional abilities are different from cognitive abilities, and they are more malleable. From the perspective of life course, adolescents are very sensitive to external interventions from family, school, etc. Some important non-cognitive abilities such as achievement motivation, self-discipline and sense of responsibility are moldable in the adolescence. During this period, through effective educational intervention and systematic learning, the development of children's social and emotional abilities can be promoted, and the children's happiness and achievement motivation can be improved.

The "Perry Preschool Education Project" is the best example of success with non-cognitive interventions. The project included 123 children aged 3 to 4 -years with an intellectual development level below 85 points in a comparative experiment that conducted educational interventions on social and emotional abilities of 58 children in the experimental group (children were randomly assigned to experimental or control group), teaching them how to be friendly with others and conducting weekly home visits to improve the parent-child relationship; the remaining 65 children in the control group received no educational intervention. Subsequently, the two groups of children were followed up until they reached adulthood. The study found that educational intervention had no impact on the cognitive abilities of these children, but greatly improved their social and emotional abilities, leading them to have happier marriages, more harmonious family relationships, better health, a higher quality of life and lower crime rates (Berrueta-Clement, 1984).

In China, in 2012, the Department of Teacher Work of the Ministry of Education of China and UNICEF cooperated on the "Social and Emotional Learning and School Management Improvement Project." The project took place in 250 project schools in five provinces (cities, districts) in western China and implemented pilot projects aimed at improving students' social and emotional abilities. Through the cooperation of school, family and community education, China is promoting the social and emotional learning of children and young people, so that students can learn self-esteem and self-management, will have social awareness and good interpersonal communication skills, can understand the emotions of others and have empathy, can form positive interpersonal relationships and creatively solve problems and can make responsible decisions in a variety of different situations (Mao et al., 2018). The project is an overall intervention that includes thematic courses, teaching reforms, changes in the school environment, and home-school cooperation. Further, the project provides an intervention template that can be used as a reference for improving the social and emotional abilities of Chinese young people.

In 2018, the China Education Innovation Research Institute of Beijing Normal University released the "21st Century Core Literacy 5C Model Research Report" (in Chinese), which listed communication and cooperation as one of the five core literacy components of young people in the 21 st century. Within this component, communication and teamwork focused on reflecting individual social skills, communication emphasized respect, understanding, empathy and cooperation emphasized the necessity of 
persistence and compromise under the premise of achieving common goals (Xu et al., 2020; Kang et al., 2020). Driven by that report, the research and intervention practice for improving Chinese adolescents' non-cognitive abilities has been further developed.

\section{Cultivation of Students' Social and Emotional Abilities is a Systematic Project}

The results of the SSES evaluation point to four aspects in the cultivation of social and emotional abilities: students, parents, teachers and schools. Many successful intervention programs in the past have shown the same characteristics. First, establish a good, close and supportive relationship between parents, teachers and children, and provide guidance. Second, ensure home, school, and workplace consistency with the quality of the community's learning environment. Third, provide skills training for children and teachers using orderly, active, focused and clear learning practices. Fourth, establish a connection project between children and adolescents, and ensure previous inputs are tracked and supplemented (OECD, 2015). The cultivation of social and emotional abilities must be regarded as an ecosystem, with multiple levels including students, teachers, parents, and communities.

At the nation level, many countries incorporate social and emotional skills learning along with academic skills learning into their education policies. Schools should be encouraged to adjust their curricula, focusing on character education and relationship education. For example, since the United States Congress approved the "Partnership in Character Education Program" in 1994, funding has been provided to state and local educational institutions to support the development of character education (US Department of Education, 2005). The same is true in South Korea; in the national curriculum revised in 2009, creativity and character education were the focus of reform, and "creative experience learning activities" were introduced to strengthen students' creativity and character education in primary and secondary school curricula (National Youth Policy Institution, 2009). In 2019, the United Kingdom's Department of Education issued a statutory guideline on relationship education, requiring that relationship education and health education is included in the compulsory courses of primary and secondary schools starting from September 2020, to help students be adequately prepared for future life (UK Department for Education, 2019).

In recent years, China has gradually realized the importance of non-cognitive abilities in curriculum reform and has promoted the cultivation of non-cognitive abilities, focusing on the training and assessment of students' non-cognitive abilities in terms of curriculum and evaluation. In this way, the education system pays attention to well-rounded development of students.

In addition, the development of social and emotional abilities must be synergetic. The OECD evaluation results show that schools, teachers, families, and communities all play an important role in improving the social and emotional capabilities of individuals. Methods that can improve social and emotional skills include optimizing the family, school and community environments, creating a family atmosphere that is conducive 
to improving social and emotional abilities, enhancing students' sense of belonging to the school, improving teacher training regarding social and emotional abilities. The teachers' own social and emotional abilities can be used to directly influence students, constructing a new type of teacher-student relationship. Acknowledging the subjectivity of families, communities, and students, respecting the wishes of students, paying attention to the emotions of stakeholders, forming a joint force for education, and striving to create an ecosystem full of emotional care are all further ways in which social and emotional skills might be improved.

\section{The Evaluation of Social and Emotional Abilities Re- quires More Localized Measurement Indicators}

As a soft skill, social and emotional abilities cannot be measured through traditional academic level tests in the same way as cognitive abilities, but instead rely mostly on self-reporting and observer reporting methods. The self-reporting method is the subjective report of emotional cognition, feeling and experience from the perspective of the experience. To avoid the subjectivity of a single perspective, such data are typically confirmed using other observers' reports. Another method of evaluation is to base evaluation on a specific theoretical model, determining the dimensions and indicators of evaluation, formulating evaluation tool scales, collecting data on students' social and emotional behavior, and evaluating students' social and emotional abilities through experiments and data.

Social and emotional abilities attach importance to performance-based and strengths-based evaluations and focus on students' strengths and growth thinking. The method used in the SSES test is to build an evaluation dimension based on the Big Five personality traits model. At the same time, it absorbs the evidence from the previous methods. In addition to students, the SSES collects relevant questionnaire information from parents, teachers, and schools, providing a check of data to ensure objective and accurate evaluation results.

Before now, limited by a lack of evaluation methods, the effectiveness of social and emotional abilities has not been effectively tested. Although some domestic scholars have tried to use foreign verified evaluation tools, such as the East Asia-Pacific early child development scales (EAP-ECDS) developed by the Asia-Pacific Early Childhood Network (Rao et al., 2014)and the caregiver-reported early development index (CREDI) for children aged 0-3 years developed by Professor Dana Charles McCoy of Harvard University in the United States(McCoy et al., 2018). The CREDI scales evaluate all aspects of child development and were introduced to China (Zhang, et al 2018), but due to the differences between Chinese and Western cultural backgrounds and educational systems, the effectiveness of its evaluation has been questioned. In the context of cultivating social and emotional abilities to promote the overall development of students, a lack of evaluation tools are a key factor restricting development of social and emotional abilities in our country. Therefore, it is urgent to build Chinese localized evaluation indicators (Zhang \& Liu, 2021). Although the SSES test still uses the inter- 
national measurement tools provided by the OECD, in terms of specific factors, more consideration is given to localization, and the design of the questionnaire can be better adapted by participating countries. Each participating country can add or modify questionnaire items. For example, in the Chinese test, the socio-economic status variables are not directly provided in the OECD Youth Social and Emotional Ability Research Database. China lists the highest education level of parents, family possessions, family equipment, and family book collection. Related basic variables are incorporated into background variables to consider the impact of background factors of Chinese families on students' social and emotional abilities.

Although we agree with the results of the SSES test, based on the representativeness and objectivity of the test results, we still have a couple of reservations about the SSES test. First, in terms of sample selection, can a sample of a city accurately represent all Chinese youth? Second, do international measurement tools suit Chinese students in a different cultural context? Can China build up localized evaluation indicators of measurement tools to promote the overall development of its students?

In summary, the construction of China's social and emotional ability measurement indicators requires the joint efforts of researchers in China, must follow the principles of science and operability, carry out a large number of empirical studies, and conduct multi-level and dynamic social and emotional ability indicators. Localized monitoring and measurement will form a localized scientific evaluation system to promote the well-rounded development of students.

\section{References}

Adhitya, D., Mulyaningsih, T., \& Samudro, B.R. (2019). The role of Cognitive and NonCognitive Skills on Labour Market Outcomes in Indonesia. Jurnal Ekonomi Malaysia, 53(1):3-16. DOI: http://dx.doi.org/10.17576/JEM-2019-53011

Alzahrani, M., Alharbi, M., \& Alodwani, A. (2019). The effect of social-emotional competence on children academic achievement and behavioral development. International Education Studies, 12(12):141-149. DOI: https://doi.org/10.5539/ies.v12n12p141

Atkins R., Turner, A., Chandola T., \& Sutton M. (2020). Going beyond the mean in examining relationships of adolescent non-cognitive skills with health-related quality of life and biomarkers in later-life. Economics \& $\mathrm{Hu}$ man Biology. 39:100923. DOI: https://doi.org/10.1016/j.ehb.2020.100923

Berrueta-Clement, J.R. (1984). Changed Lives: The Effects of the Perry Preschool Program on Youths through Age 19. Monographs of the High/Scope Educational Research Foundation, Number Eight. Monograph Series, High/Scope Foundation, 600 North River Street, Ypsilanti, MI 48197.

Bowles, S. \& Gintis, H. (2002). Schooling in capitalist America revisited. Sociology of Education, 75(1):1-18. DOI: https://doi.org/10.2307/3090251 
Zhao et al. China Report on the Global Youth Survey of Social and Emotional Skills by the OECD.

CASEL. (March 01, 2003). Safe and Sound: An

Educational Leader's Guide to Evidence-

Based Social and Emotional Learning (SEL)

Programs. Retrieved August 17, 2021, from

https://files.eric.ed.gov/fulltext/ED482011.p df

Chernyshenko, O.S., Kankaraš, M., \& Drasgow, F. (2018). Social and emotional skills for student success and well-being: Conceptual framework for the OECD study on social and emotional skills. ISSN: 19939019 (online) DOI:

https://doi.org/10.1787/19939019

Core Literacy Research Group. (2016). Chinese students develop core literacy. Journal of the Chinese Society of Education, 37(10):1-3.

[Chinese]

http://www.cnki.com.cn/Article/CJFDTotalZJYX201610003.htm

Department of Education and Skills. (2012). A Framework for Junior Cycle. Retrieved September 11, 2021, from

https://assets.gov.ie/24477/47baa8cfe8164f3 89e970538883d71d7.pdf

Du, W. (December 20, 2019 ). What educational enlightenment does the PISA test bring to educational evaluation? Modern Education Daily, 12-18. [Chinese] Retrieved September 11, 2021, from

http://studio.nxeduyun.com/index.php?r=stu dio/post $/$ view\&sid=924\&id=196720

Durlak, J.A., Weissberg, R.P., Dymnicki, A.B., Taylor, R.D., \& Schellinger, K.B. (2011). The impact of enhancing students' social and emotional learning: A meta-analysis of school-based universal interventions. Child Development, 82(1):405-432. DOI:

https://doi.org/10.1111/j.1467$\underline{\text { 8624.2010.01564.x }}$

Elias, M.J., \& Haynes, N.M. (2008). Social competence, social support, and academic achievement in minority, low-income, urban elementary school children. School Psychology Quarterly, 23(4):474-495. DOI: https://psycnet.apa.org/doi/10.1037/10453830.23.4.474

Elias, M.J., Zins, J.E., Weissberg, R.P., Frey, K.S., Greenberg, M.T., Haynes, N.M., Kessler, R., Schwab-Stone, M.E., \& Shriver, T.P. (1997). Promoting Social and Emotional
Learning: Guidelines for Educators. Alexandria: ASCD.

Fang, L. (2020). Status quo and characteristics of OECD social and emotional skills assessment project. Shanghai Journal of Educational Evaluation, 9(5):44-49. [Chinese] DOI:

https://doi.org/10.13794/j.cnki.shjee.2020.00 72

Frydenberg, E., Martin, A. J., \& Collie, R. J. (2017). Social and emotional learning in Australia and the Asia-Pacific. Social and emotional learning in the Australasian context. Melbourne, Australia: Springer Social Sciences.

Gao, X., Chen, H., Wu, J., \& Huang, Z. (2021). Task performance: Report on the study on social and emotional skills of Chinese adolescence (I). Journal of East China Normal University (Educational Sciences), 39(9):3346. [Chinese] DOI: https://doi.org/10.16382/j.cnki.1000$\underline{5560.2021 .09 .002}$

Gold, S. (2009). Measuring social competence, task competence and self-protection in an organisational context (Doctoral dissertation, University of Newcastle). http://hdl.handle.net/1959.13/44576

Haggerty, K., Elgin, J., \& Woolley, A. (2011). Social-emotional learning assessment measures for middle school youth. Social Development Research Group. University of Washington: Raikes Foundation. Retrieved September 11, 2021, from https://schoolguide.casel.org/uploads/sites/2/ 2018/12/DAP-Raikes-FoundationReview.pdf

Hanushek, E. A. (2013). Economic growth in developing countries: The role of human capital. Economics of Education Review, 37:204-212. DOI: https://doi.org/10.1016/j.econedurev.2013.04 .005

Heckman, J.J., \& Kautz, T. (2012). Hard evidence on soft skills. Labour Economics, 19(4):451-464. DOI:

https://doi.org/10.1016/j.labeco.2012.05.014

Heckman, J.J., Stixrud, J., \& Urzua, S. (2006). The effects of cognitive and noncognitive abilities on labor market outcomes and social behavior. Journal of Labor Economics, 
Zhao et al. China Report on the Global Youth Survey of Social and Emotional Skills by the OECD.

24(3):411-482. DOI:

https://doi.org/10.1086/504455

Huang, G., \& Xie, Y. (2017). The Influence of Cognitive Ability and Non-cognitive Ability on Youth Labor Income Return. China Youth Study, 29(2):56-64+97. [Chinese] DOI: https://doi.org/10.19633/j.cnki.112579/d.2017.02.009

Huang, Z. (2020). Social and emotional competence: key factors affecting success and happiness. Global Education, 49(6):102-112. [Chinese]

http://www.cnki.com.cn/Article/CJFDTotalWGJN202006009.htm

Huang, Z., Wang, Q., Chen, H., \& Gao, X. (2021). Engaging with others: The report on the study on social and emotional skills of Chinese adolescents (V). Journal of East China Normal University (Educational Sciences), 39(9):93-108. [Chinese] DOI: https://doi.org/10.16382/j.cnki.10005560.2021.09.006

Huy, Q.N. (1999). Emotional capability, emotional intelligence, and radical change. Academy of Management Review, 24(2):325345. DOI:

https://doi.org/10.5465/amr.1999.1893939

Kang, C., Xu, G., Wei, R., Liu, J., Zheng, Y., \& Liu, Y., Gan, Q., \& Ma, L. (2020). Openmindedness: Report on the study on social and emotional skills of Chinese adolescence (IV). Journal of East China Normal University (Educational Sciences), 39(9):77-82.

[Chinese] DOI:

https://doi.org/10.16382/j.cnki.10005560.2020.02.007

Kankaraš, M. (2017). Personality matters: Relevance and assessment of personality characteristics. ISSN: 19939019 (online) https://doi.org/10.1787/19939019

Kankaraš, M., Feron, E., \& Renbarger, R. (2019). Assessing students' social and emotional skills through triangulation of assessment methods. ISSN: 19939019 (online)

https://doi.org/10.1787/19939019

Lendrum, A., \& Humphrey, N. (2010). Implementing social and emotional aspects of learning (SEAL) in secondary schools in England: Issues and implications. Manchester: University of Manchester.
Liu, D. (2017). How Trait Emotional Intelligence Affects Students' Academic Achievement: A Case Study of Primary School Mathematics. Journal of Educational Science of Hunan Normal University, 24(6):44-50. [Chinese] DOI: https://doi.org/10.19503/j.cnki.1671$\underline{6124.2017 .06 .007}$

Liu, Z., \& Liang, C. (2021). Taking the cultivation of students' social and emotional abilities as a powerful starting point for the integration of the five educations. Journal of the Chinese Society of Education, 42(2):1-5+11. [Chinese]

https://kns.cnki.net/kcms/detail/detail.aspx?d bcode $=$ CJFD \&dbname $=$ CJFDLAST2021\&fi lename=ZJYX202102009\&uniplatform=NZ KPT\&v=gJzpcD\%25mmd2FFP30EHkgJkT vxhsRR\%25mmd2B10WF1BvjKqLp6Fu\%2 5mmd2B7c1\%25mmd2FQOmhYZG21rUnf $\underline{80 s c n n}$

Liu, Z., Zhu, R., Cui, H., \& Huang, Z. (2021). Emotional regulation: Report on the study on social and emotional skills of Chinese adolescence (II). Journal of East China Normal University (Educational Sciences), 39(9):47-61. [Chinese] DOI:

https://doi.org/10.16382/j.cnki.1000$\underline{5560.2021 .09 .003}$

Mao, Y., Du, Y., Yi, K., \& Wen, S. (2018). School improvement based on the cultivation of students' social and emotional abilities-the exploration and practice of the Ministry of Education-UNICEF "Social Emotional Learning" project. Primary and Secondary School Management, 32(11):31-33. [Chinese] DOI: https://doi.org/10.3969/j.issn.10022384.2018.11.009

McCoy, D.C., Waldman, M., Team, C.F., \& Fink, G. (2018). Measuring early childhood development at a global scale: Evidence from the Caregiver-Reported early development instruments. Early Childhood Research Quarterly, 45:58-68. DOI:

https://doi.org/10.1016/j.ecresq.2018.05.002

Ministry of Education of the People's Republic of China, MOE. (June 3, 2013). Opinions of the Ministry of Education on Promoting the Reform of Comprehensive Evaluation of Educational Quality in Primary and Second- 
Zhao et al. China Report on the Global Youth Survey of Social and Emotional Skills by the OECD.

ary Schools. [Chinese] Retrieved September 14, 2021, from

http://www.moe.gov.cn/srcsite/A06/s3321/2

01306/t20130608_153185.html

Mueller, G. \& E. Plug. 2006. Estimating the effect of personality on male-female earnings. Industrial and Labor Relations Review, 60(1):3-22. DOI:

https://doi.org/10.1177\%2F00197939060600 0101

Mýtna Kureková, L., Beblavý, M., Haita, C., \& Thum, A.E. (2016). Employers' skill preferences across Europe: between cognitive and non-cognitive skills. Journal of Education and Work, 29(6):662-687. DOI: https://doi.org/10.1080/13639080.2015.1024 $\underline{641}$

National Youth Policy Institution. (2009). Introduction to creative activities, Ministry of Education. Retrieved September 11, 2021, from

https://www.nypi.re.kr/atchfile/binaryAtchfil e.do?vchkcode $=$ SAkYJ98fR $1 \mathrm{kw}$

OECD (2021). Beyond Academic Learning:

First Results from the Survey of Social and Emotional Skills, OECD Publishing, Paris,

Retrieved September 11, 2021, from https://doi.org/10.1787/92a11084-en

OECD. (2015). Skills for Social Progress: The Power of Social and Emotional Skills, OECD Skills Studies, OECD Publishing. Retrieved September 11, 2021, from https://www.oecd.org/education/skills-forsocial-progress-9789264226159-en.htm

OECD. (2017). Social and Emotional Skills: Well-being, Connectedness and Success. Retrieved September 10, 2021, from http://www.oecd.org/education/ceri/thestudy onsocialandemotionalskills.htm

OECD. (September 7, 2021). OECD Survey on Social and Emotional Skills Technical Report. Retrieved September 10, 2021, from http://www.oecd.org/education/ceri/thestudy onsocialandemotionalskills.htm

Osher, D., Kidron, Y., Brackett, M., Dymnicki, A., Jones, S., \& Weissberg, R.P. (2016). Advancing the Science and Practice of Social and Emotional Learning: Looking Back and Moving Forward. Review of Research in Education, 40(1):644-681. DOI:
https://doi.org/10.3102\%2F0091732X16673 595

Payton J., Resnik, H.,Weissberg, R. P., Durlak, J.A., Dymnicki A.B., \&Taylor, R. D., et al. (2010). Collaborative for Academic, Social and Emotional Learning (CASEL). Springer US.

http://citeseerx.ist.psu.edu/viewdoc/summar y?doi=10.1.1.548.3408

Rao, N., Sun, J., Ng, M., Becher, Y., Lee, D., Ip, P., \& Bacon-Shone, J. (2014). Validation, finalization and adoption of the East AsiaPacific early child development scales (EAP-ECDS). New York: UNICEF. http://www.arnec.net/wpcontent/uploads/2015/07/EAP-ECDS-FinalReport1.pdf

Succi, C., \& Canovi, M. (2020). Soft skills to enhance graduate employability: comparing students and employers' perceptions. Studies in Higher Education, 45(9):1834-1847. DOI: https://doi.org/10.1080/03075079.2019.1585 $\underline{420}$

Tan, J.P.L., Koh, E., Chan, M., Costes-Onishi, P., \& Hung, D. (February, 2017). Advancing 21 st century competencies in Singapore. National Institute of Education, Nanyang Technological University, Singapore. Retrieved September 10, 2021, from https://www.researchgate.net/publication/31 7279438_Advancing_21st_Century_Compet encies_in_Singapore

Tang, Y., Zheng, J., Sun, X., \& Huang, Z. (2021). Tang, Y., Zheng, J., Sun, X., \& Huang, Z. (2021) Collaboration: Report on the study on social and emotional skills of Chinese adolescence (III). Journal of East China Normal University (Educational Sciences), 39(9):62-76. [Chinese] DOI: https://doi.org/10.16382/j.cnki.1000$\underline{5560.2021 .09 .004}$

Turner, J. H., \& Stets, J. E. (2005). The sociology of emotions. Cambridge University Press.

UK Department for Education. (April 5, 2019). Relationships education, relationships and sex education (RSE) and health education: FAQs. Retrieved September 11, 2021, from https://www.gov.uk/government/news/relati onships-education-relationships-and-sexeducation-rse-and-health-education-faqs 
Zhao et al. China Report on the Global Youth Survey of Social and Emotional Skills by the OECD.

UNESCO. (April 05, 2019)._ Social and Emotional Skills and the Education 2030 agenda [EB/OL]. Retrieved September 10, 2021, from https://en.unesco.org/events/social-andemotional-skills-and-education-2030-agenda

US Department of Education. (2005, May 31). Character Education. Our Shared Responsibility. Retrieved September 11, 2021, from http:

https://www2.ed.gov/admins/lead/character/ brochure.html

Vaillant, G. (2012). Triumphs of Experience: The Men of the Harvard Grant Study. Cambridge, MA and London, England: Harvard University Press. DOI:

https://doi.org/10.4159/harvard.9780674067 $\underline{424}$

Wigelsworth M., Humphrey N., Kalambouka A., $\&$ Lendrum A. (2010). A review of key issues in the measurement of children's social and emotional skills. Educational Psychology in Practice, 26(2):173-186. DOI: https://doi.org/10.1080/02667361003768526

World Economic Forum. (2016, March 10). New vision for education: Fostering social and emotional learning through technology. Geneva: World Economic Forum. Retrieved September 11, 2021, from

https://www.weforum.org/reports/newvision-for-education-fostering-social-andemotional-learning-through-technology

World Economic Forum. (2016, March). New vision for education: Fostering social and emotional learning through technology. Geneva: World Economic Forum. Retrieved September 11, 2021, from http://hdl.voced.edu.au/10707/443447

Xu, G., Wei, R., Liu, J., Li, J., Kang, C., Ma, L., Gan, Q., \& Liu, Y. (2020). Huang, Z., Wang, Q., Chen, H., \& Gao, X. (2021). Engaging with others: The report on the study on social and emotional skills of Chinese adolescents (V). Journal of East China Normal University (Educational Sciences), 39(9):8396. [Chinese] DOI:

https://doi.org/10.16382/j.cnki.1000$\underline{5560.2020 .02 .008}$

Yuan, Z., Huang, Z., Li, J., \& Zhang, J. (2021). Report on the Development Level of Chinese Adolescents' Social and Emotional
Ability. Journal of East China Normal University (Educational Sciences), 39(9):1-32.

[Chinese] DOI:

https://doi.org/10.16382/j.cnki.1000-

$\underline{5560.2021 .09 .001}$

Zhang, J., \& Liu, D. (2021). Three Questions on the Evaluation of Social and Emotional Ability. Journal of the Chinese Society of Education, 42(2):18-24. [Chinese]

https://kns.cnki.net/kcms/detail/detail.aspx?d bcode $=$ CJFD $\&$ dbname $=$ CJFDLAST2021\&fi lename $=$ ZJYX202102012\&uniplatform $=\mathrm{NZ}$ KPT\&v=gJzpcD\%25mmd2FFP31nYs5nyy7 yPVRIIGpGq0APwzRB\%25mmd2BmFHF9 mmUwA27io1Wu0CHNCt3ila

Zhang, J., Tang, Y., Guo, J., \& Shao, Z. (2021). Technical Report on the Assessment of Social and Emotional Ability of Chinese Adolescents. Journal of East China Normal University (Educational Sciences), 39(9):109-

126. [Chinese] DOI:

https://doi.org/10.16382/j.cnki.1000$\underline{5560.2021 .09 .007}$

Zhang, X. (2020). Non-cognitive abilities stimulate positive growth. China Education Daily, 07-03.

https://news.ruc.edu.cn/archives/282383

Zhang, Y., Zhao, J., Shan, W., Young, M.E., He, Y., Mao, H., Qu, J., Zhao, Z., \& Jiang, F. (2018). Early childhood development assessment tool and its development and application in China. Chinese Journal of Pediatrics, 56(2):84-87. [Chinese] DOI: https://doi.org/10.3760/cma.j.issn.0578$\underline{1310.2018 .02 .002}$

Zhou M.M., \& Ee J. (2012). Development and Validation of Social Emotional Competence Questionnaire (SECQ). Emotional Education, 4(2):27-42.

https://www.um.edu.mt/library/oar//handle/1 23456789/6140

Zhou, Q., Main, A., \& Wang, Y. (2010). The relations of temperamental effortful control and anger/frustration to Chinese children's academic achievement and social adjustment: A longitudinal study. Journal of Educational Psychology, 102(1): 180. DOI: https://psycnet.apa.org/doi/10.1037/a001590 $\underline{8}$ 
Zhao et al. China Report on the Global Youth Survey of Social and Emotional Skills by the OECD.

Received: 18 September 2021

Revised: 22 September 2021

Accepted: 23 September 2021 